\title{
Design and Development of GRF Aqua Silencer by E-Glass Composite for Reduction of Noise and Particulate Matter in Automotive Diesel Engine
}

\author{
M. Sinha ${ }^{1 *}$, R. Ranjan ${ }^{2}$ and R. K. Tyagi ${ }^{1}$ \\ ${ }^{1}$ Department of Mechanical Engineering, Amity University, Noida, India \\ *Email: medhavisinha.02@ gmail.com \\ Phone: +918826118396 \\ ${ }^{2}$ Department of Mechanical Engineering, National University of Singapore, Singapore
}

\begin{abstract}
As per the recent statistical data, the consumption of fuel has increased from 1965 to 2012 at a very high rate. Earlier, we used to relay mostly on coal for running steam engines, and with the advancement of technology, this switched over to gasoline, diesel, natural gas and alternative fuels. Most of the emission coming from automotive engines was the main contributor to air pollution. An Aqua silencer composed of E glass-based composite was introduced to avoid the release of such gases directly into the atmosphere from diesel engines. It was manufactured using core moulding and vacuum bagging technology and was fitted to the exhaust pipe of the diesel engine to treat the toxic gasses before releasing to the atmosphere. Other than reducing the regulated emission, it also reduced particulate matter significantly. The particulate matter was reduced using an activated charcoal layer. The noise and particulate level were found to be less by 40 and $93 \%$ respectively when compared with the conventional silencer. Besides this, it has ease of installation. The current paper discussed the utilisation of this innovative mechanism in automobiles and its contribution to various fields such as refineries and chemical processing units.
\end{abstract}

Keywords: Aqua silencer; GRF composites; noise; particulate matter.

\section{INTRODUCTION}

Recently it was observed that the number of on-road vehicles had increased significantly with the increase in population and technological advancement. The amount of automotive emission and industrial waste discharge were also increased similarly. Gasoline and diesel fuels are a mixture of hydrocarbons. In a perfect combustion process, oxygen in the air should convert all hydrocarbons into the water, carbon dioxide, and nitrogen. But, the combustion process is imperfect which produce several by-product such as carbon dioxide, oxides of nitrogen, unburned hydrocarbon and particulate matter. These are the most common emission of diesel engine [1].

The automotive vehicles particularly diesel engines are the prime causes of various hazardous emissions such as particulate matter $\left(\mathrm{PM}_{2.5}\right)$. It is very fine and has various detrimental effects on human health. It can be perceived by various studies that the effect of the harmful emissions from the vehicular systems is considerably more on human begins as they are directly in contact with the polluted environment in urban areas than the harmful emissions released by the coal-fired power plants as they are 
mostly located in remote areas and the human life does not have direct contact with them. The main constituents of PM2.5 emitted from automobiles are carbon compounds such as carbon black and organic aerosol. The amount of carbon black discharged from the automobiles relies on numerous considerations such as the type of the engine, its operation in different circumstances, and the type of emission reduction system used. It is observed that the black carbon emission in a diesel engine is comparatively greater than the organic aerosol emissions for the same working conditions [2].

According to several epidemiological studies, very fine particles of vehicular emissions are the most hazardous emissions for human health. These super fine particles are so small that they can enter the lungs of the human beings with the inhaled air and can further enter into the bloodstream. Air pollution is extremely hazardous for human beings and leads to various threatening respiratory disease such as asthma, lung cancer, bronchitis, Chronic Obstructive Pulmonary Disease, Leukaemia etc. It can also lead to several kinds of Cardiovascular Diseases and premature deaths in infants due to as asphyxiation as their bodies are sometimes not fully ready to handle various kinds of reactions due to the dissolution of particulate matter in their fragile bodies. Besides its detrimental effects on the health of human being's air pollution has its direct harmful effects on the health of plants life. It can lead to growth reduction, leaf damage, insect invasion and other issues for the plants' well-being.

The detrimental effects of air pollution for both plants and human life were the prime concern of Council Directive 1999/30/EC which has instructed that the PM2.5 concentrations should be every day supervised and recorded to be presented to the European Commission. But the only drawback was that the Council Directive 1999/30/EC had not posed any limits and tribulations for PM2.5. Keeping this account of PM 2.5 was the responsibility of the member states. A decade later the Council Directive 2008/50/EC was established on Ambient Air Quality and Cleaner Air for Europe. This council states the following limits for PM2.5:

i. The Average Exposure Indicator (AEI) of PM 2.5 must be decreased by at least $20 \%$ of the PM2.5 levels in 2010 in each member state.

ii. The Average Exposure Indicator (AEI) of PM 2.5 is $20 \mu \mathrm{g} / \mathrm{m}^{3}$ for urban areas by 2015.

iii. The maximum value for the annual average PM2.5 level is set to $25 \mu \mathrm{g} / \mathrm{m}^{3}$ by 2015.

iv. The annual average PM2.5 limit has been reduced to $20 \mu \mathrm{g} / \mathrm{m}^{3}$ for the year 2020 $[3,4]$.

Engine noise can be classified into aerodynamic and surface radiated noise. The aerodynamic noise consists of air intake and exhaust system noise. This type of noise can be reduced by use of air intake system and by mufflers at the exhaust system. The surface noise can be measured by using lead covering, surface vibration and acoustic technique. Undesired noise from any source is seriously harmful to the well-being and health of the human beings and many undesired effects are produced on the health of mankind such as lack of sleep and lack of concentration because of noise therefore it is really necessary to control the amount of noise generated from any kind of source $[5,6]$.

The automotive vehicles extract their power due to the running of their internal combustion engines. The main source for power generation in the automotive engine is the combustion of fuel which leads to the generation of an unfavourable and detrimental environment for human beings with the production of various harmful emissions and high sound levels. The consequences of these detrimental effects have attracted various 
researchers and analyst to investigate and study for various pollution and sound reducing techniques due to automobiles for the well-being of human beings. Some pollution reducing facts in the internal combustion engine are:

i. Heating of catalytic converter in the initial phase of engine starting.

ii. Cleaning of the catalytic converter

iii. Using modified intake manifold devices for increasing fuel burning efficiency

iv. Using alternative fuel (hydrogen, $\mathrm{CNG}, \mathrm{PNG}$, etc.)

Various tests were performed by the heating of catalytic converter to eliminate in the delay period of temperature gain from $0^{\circ} \mathrm{C}$ to $750^{\circ} \mathrm{C}$. It was perceived after the experimental investigation that exhaust emissions such as $\mathrm{HC}, \mathrm{CO}$, and $\mathrm{NO}_{\mathrm{X}}$ reduced significantly with the reduction in delay time [7]. The spark engine catalytic converter conversion efficiency was studied for new, old and without a converter. The results obtained by experimental investigation conclude that new catalytic converter is more efficient than the old. It causes a maximum reduction in $\mathrm{CO}, \mathrm{HC}$, and $\mathrm{NO}_{\mathrm{X}}$ by $81 \%$, $83 \%$ and $93 \%$ respectively [8].

The exhaust emissions of an SI engine were scrutinised, and an investigation was performed with the utilisation of gasoline-hydrogen blends considering different ignition timings and conditions. It can be perceived from the experimental investigation that the $\mathrm{HC}$ emissions decrease linearly, and the $\mathrm{NO}_{\mathrm{X}}$ concentration increases exponentially with the increase in ignition timing. It can also be observed that the increase in hydrogen fraction in the mixture blend leads to a noticeable reduction in $\mathrm{HC}$ and $\mathrm{NO}_{\mathrm{x}}$ emissions [9]. Aqua silencer is a mechanical system which has a huge potential of reducing hazardous emissions, as well as noise emitted by engine exhaust systems but, the conventionally used aqua silencers, have their outer body composed of cast iron and there are certain drawbacks associated with them. Some of the drawbacks with the conventional aqua silencers are:

i. Very heavy in weight in comparison to the conventional silencers.

ii. They get corroded over time and use.

The drawbacks mentioned above associated with the conventional aqua silencer needs consideration, and the best solution to the problems associated with the conventional aqua silencers are the utilisation of composites. The composites have properties such as lightweight, high strength to weight ratio, low thermal conductivity, corrosion resistance as well as manufacturing economy. With these properties, they can replace many engineering materials such as cast iron, steel and aluminium, and that too with many more times better performance. If composite materials replace, the components made by steel, a weight saving of about $60 \%$ to $80 \%$ can be achieved and similarly the replacement of aluminium goods by composites can give about $20 \%$ to $50 \%$ of weight saving. Thus, it can be understood that composite materials can be treated as the best materials for almost every engineering application. The current study, therefore, focuses on minimising the hazardous pollutants and the noise level of the diesel engine exhaust system by the utilisation on an innovative aqua silencer by the utilisation of E glass composite to eliminate the shortcomings in the conventional aqua silencer [10].

The prime objective of this work is to develop an efficient system which could control not only air pollutants but also could minimise noise level in a diesel engine. The diesel engines emit various hazardous gases as their emissions such as $\mathrm{CO}, \mathrm{NO}_{\mathrm{x}}$, $\mathrm{HC}$, particulate matter etc., besides high noise. The high noise can cause many ill effects to the living being. Hence, the removal of pollutants and the reduction of noise is 
the prime concern of the present study. Many researchers are focusing on the same subject because of the criticality of the issue, and many solutions are also projected for the same. But most of the solutions are very expensive and non-economical. In the existing study therefore, the focus has been established on the adsorption technique with the utilisation of some low-cost chemicals such as activated charcoal. The adsorption technique is economical and feasible technique. The following factors are considered while designing the aqua silencer for the engine exhaust system:

i. It should be light in weight.

ii. It should have high mechanical and chemical resistance.

iii. The hazardous emissions should be minimised.

iv. The noise level should be reduced.

\section{MATERIALS AND METHOD}

Various components are required for the fabrication and assembly of a GFR aqua silencer. Figure 1 shows a perforated tube. It is the first component required for the fabrication of the aqua silencer. It is a metallic tube having a length of about $305 \mathrm{~mm}$ and a diameter of $38 \mathrm{~mm}$. It has various holes of different diameters such as 6, 8, 9 and $11 \mathrm{~mm}$ drilled through its entire length. The main function of the perforated tube is the transformation of large bubbles to small bubbles.

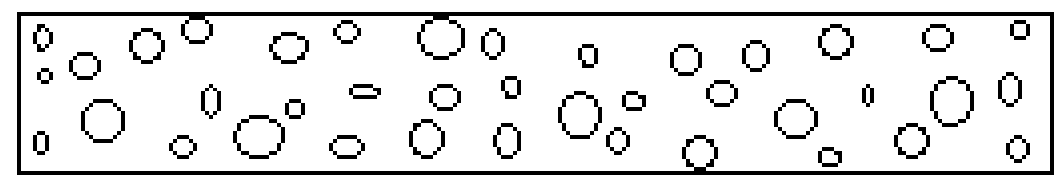

Figure 1. Perforated tube

The charcoal layer also called as the activated charcoal layer is the second component required for the fabrication of the aqua silencer. The perforated tube is directly coated with $30-40 \mathrm{~mm}$ thick the charcoal layer. It is the main element in the adsorption technology. Its absorbing capacity is directly proportional to its surface area. The charcoal is heated for more than 10 to 12 hrs to very high temperatures, above $800^{\circ} \mathrm{C}$ until it becomes highly porous for its production.

The outer shell is the third component required for the fabrication of the aqua silencer. Its CAD model is represented by Figure 2. It has a length of about $305 \mathrm{~mm}$ and diameter of about $188 \mathrm{~mm}$. In the present investigation, an innovative outer shell composed of GFR composite is utilised. It is the main component where all the components of the aqua silencer are placed. It consists of the inlet and outlet water exhaust tube in its composition. The outer shell is manufactured using lost core moulding technique using E glass fibres as reinforcement; epoxy Araldite AW 106 as the resin and HV $953 \mathrm{IN}$ as the hardener for which firstly the FRP mould was developed. After the solidification of the mould, the resin harder mix and the glass fibres are layered over each other one by one until the desired thickness is achieved by using vacuum bagging technique. It is left for curing for about $72 \mathrm{hrs}$. After this step, the FRP mould is melted out and our final GFR inlet passage is cleaned properly using acetone before actual investigation. 


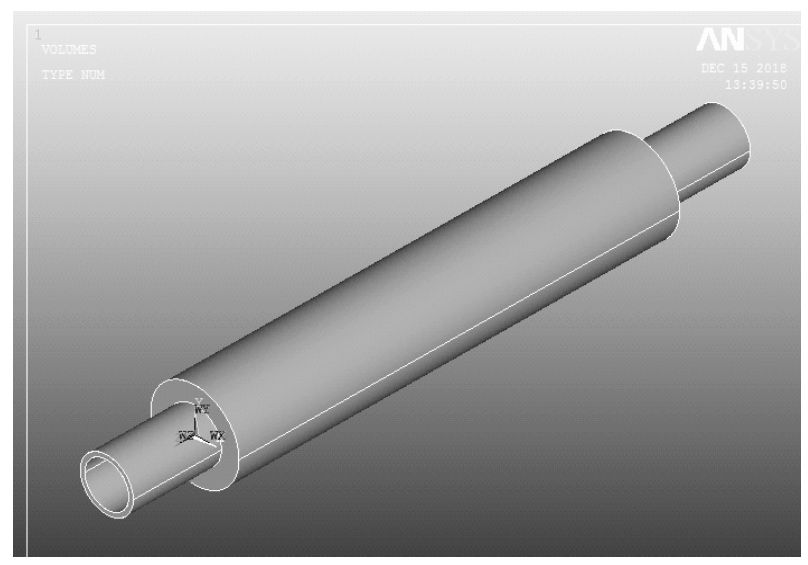

Figure 2. Outer shell.

Besides, there are some secondary components also. Figure 3 shows the orientations in the aqua silencer. The non-return valve is the first secondary component required for the fabrication and assembly of the aqua silencer. Its main function is to allow only one directional flow of the liquid through it. The base pressure for its working is called as the cracking pressure. The exhaust gases generate a lot of pressure, and the magnitude of this pressure is much higher than cracking pressure. Because the fitted valve is a non-return valve, therefore, it eliminates the effect of back pressure generated by exhaust gases, there is the negligible effect of the non-return valve on brake power of the engine.

The flange is the second secondary component required for the fabrication and assembly of the aqua silencer. Its main function is to join the silencer and the engine together. The $\mathrm{H}$ - nipple is the third secondary component required for the fabrication and assembly of the aqua silencer. It is a device which is used to connect two pipes. It consists of two threaded sides.

\section{Construction and Working}

The schematic diagram of the aqua silencer is shown in Figure 3, and the Figure 4 shows the experimental set up for different types of test and investigations carried out in the current paper. As can be seen from the figures, the exhaust gases enter the aqua silencer through the exhaust pipe. The perforated tube is installed next to the exhaust pipe. The perforated tube is, therefore, the first component of the aqua silencer where the exhaust gases enter. On their way through the perforated tube, the transformation of large bubbles to small bubbles takes place. The perforated tube is coated with a thick layer of activated charcoal enveloped with a metallic mesh. The activated charcoal has high adsorption capacity and therefore adsorbs large extent of hazardous gases thus purifying the gases. These gases are then released to the top of the arrangement which has a small vent for the exit of the exhaust gases. The non-return valves check the backflow of gases, mounted on the inlet of the exhaust gases. All the constituents mentioned above of the aqua silencer are surrounded by water.

An AKV-5, Kirloskar water cooled diesel engine of 5hp (3.7 KW) power was assembled to the innovative aqua silencer as shown in figure 4. It has seven main entities, an engine, the water surrounded aqua silencer, an inlet pipe for engine exhaust gases, exhaust pipe, inlet and an outlet pipe for water and the stand for aqua silencer 
support. The figure shows the engine connected to the aqua silencer unit through an exhaust inlet pipe. It is the passage through which the exhaust gases emitted by the engine enter the aqua silencer. The emitted gases are worked upon for purification in the aqua silencer, and the much-purified gases are released from the aqua silencer through the exhaust pipe as shown in figure 4. The engine was run for about 15 to 20 minutes before actually starting with the experimental investigations. All the tests were performed when the engine reached its optimum working condition after the initial start.

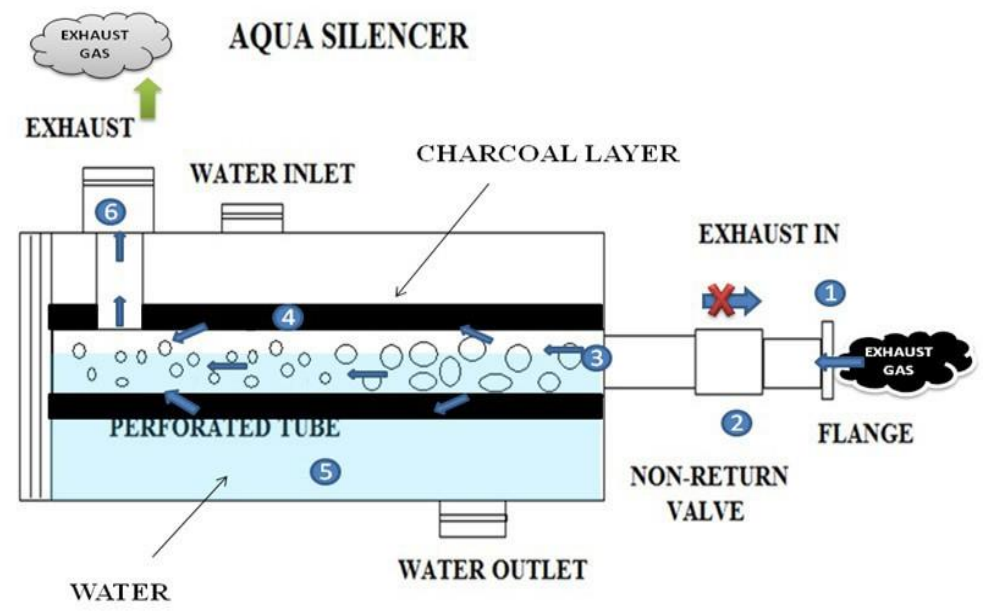

Figure 3. Schematic diagram of aqua silencer.

\section{RESULTS AND DISCUSSION}

\section{Engine Test}

The performance tests for the Engine were performed on an AKV-5, Kirloskar water cooled diesel engine of $5 \mathrm{hp}(3.7 \mathrm{KW})$ power. The specifications of the engine under investigation are given in table 1 . Various tests were conducted at various load conditions at the constant speed of $1500 \mathrm{rpm}$, and the pressure for fuel injection was kept constant at 180 bars. The engine load was measured with steady-state eddy current dynamometer.

Table 1. Specification of engine under investigation (diesel)

\begin{tabular}{ll}
\hline Components & Specification \\
\hline Number of cylinders & Single cylinder \\
Cylinder bore & $80 \mathrm{~mm}$ \\
Stroke length & $110 \mathrm{~mm}$ \\
\hline
\end{tabular}

\section{Noise Test}

Noise is an undesirable issue related to the engine. The sound level meter was used to measure the noise produced by the diesel engine with and without an aqua silencer. The $\mathrm{x}, \mathrm{y}$ coordinates (distance and position) of sound level meter from tailpipe were $65 \mathrm{~cm}$, 
$45 \mathrm{~cm}$, at the time of experiment environment noise level was $2.6 \mathrm{~dB}$. Specification of the sound level meter is tabulated below in Table 2.

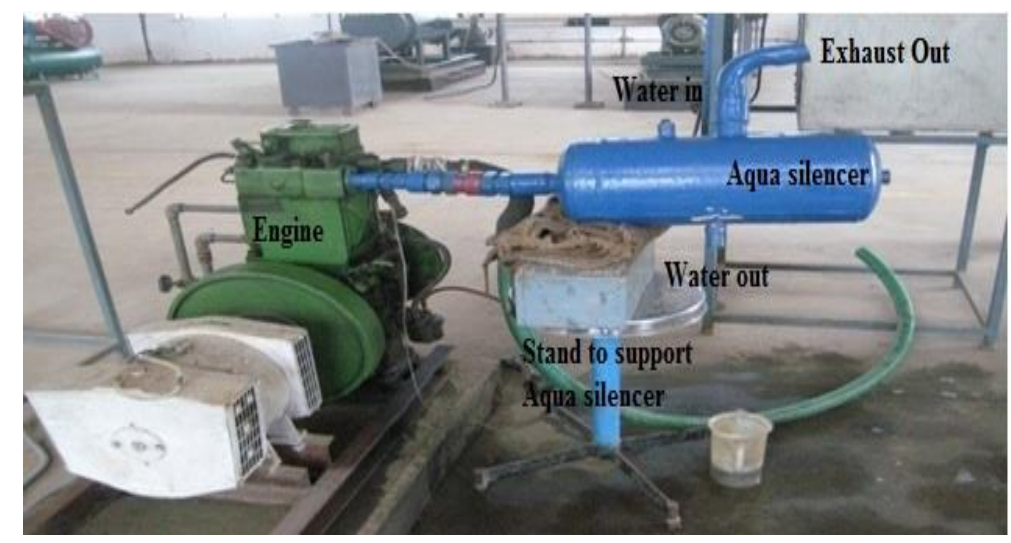

Figure 4. Experimental setup

Table 2. Specification of sound level meter.

\begin{tabular}{ll}
\hline Item & Specification \\
\hline Type & Digital Sound Level Meter \\
Range & $40-130 \mathrm{~dB}$ \\
Microphone used & Utilises $0.5 "(12.7 \mathrm{~mm})$ \\
& Electrets condenser microphone \\
Accuracy and resolution & $\pm 2 \mathrm{~dB}$ accuracy with $0.1 \mathrm{~dB}$ resolution \\
\hline
\end{tabular}

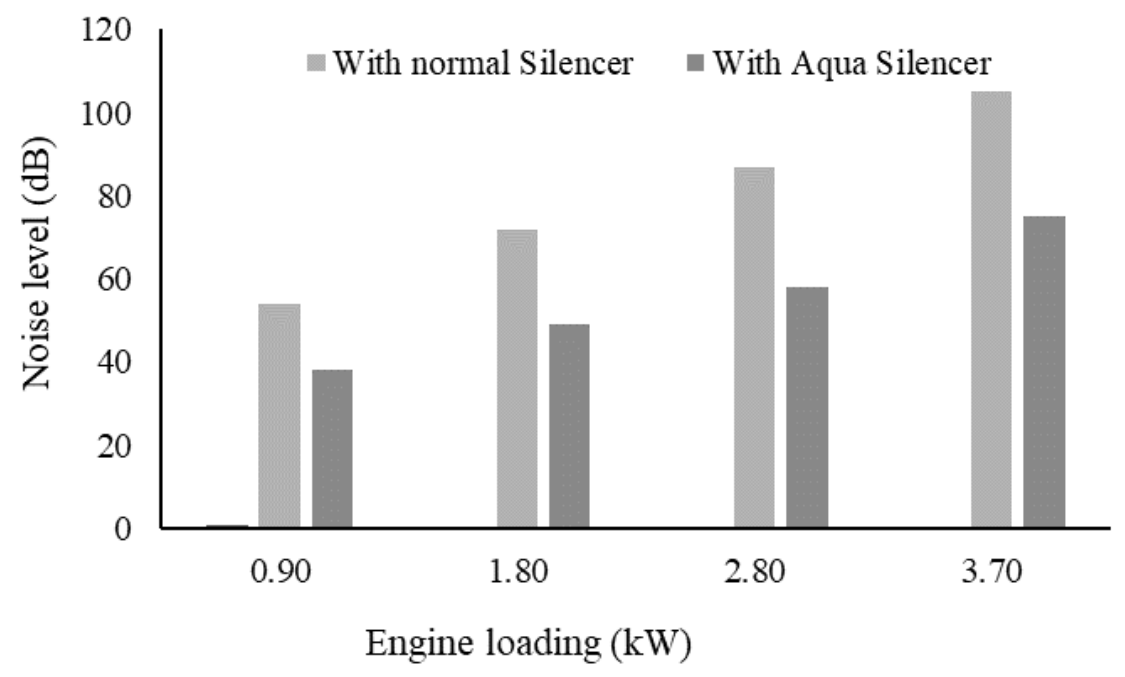

Figure 5. Noise level at different loadings.

After conducting the test and recording results at 25, 50, 75 and full load conditions; it was found that there was a significant decrease in the engine noise level. It reduced from $54 \mathrm{~dB}$ to $38 \mathrm{~dB}, 72 \mathrm{~dB}$ to $49 \mathrm{~dB}, 87 \mathrm{~dB}$ to $58 \mathrm{~dB}$ and $105 \mathrm{~dB}$ to $75 \mathrm{~dB}$ at $25 \%$, $50 \%, 75 \%$ and full load conditions respectively. The result was drawn at part load to full load condition in figure 5. The audibility of the sound generated inside water is very less 
in comparison to the audibility to the sound generated in the atmosphere. The minute sprockets present in the molecules of the water are responsible for the lowers the amplitude of the sound consequently decreasing the level of sound under water. It also reduced vibrations in the system.

\section{Emission Test}

The emission readings were recorded with the help of MRU DELTA 1600L exhaust gas analyser. The readings were recorded at constant $1500 \mathrm{rpm}$ and full load condition of $3.7 \mathrm{kw}$.

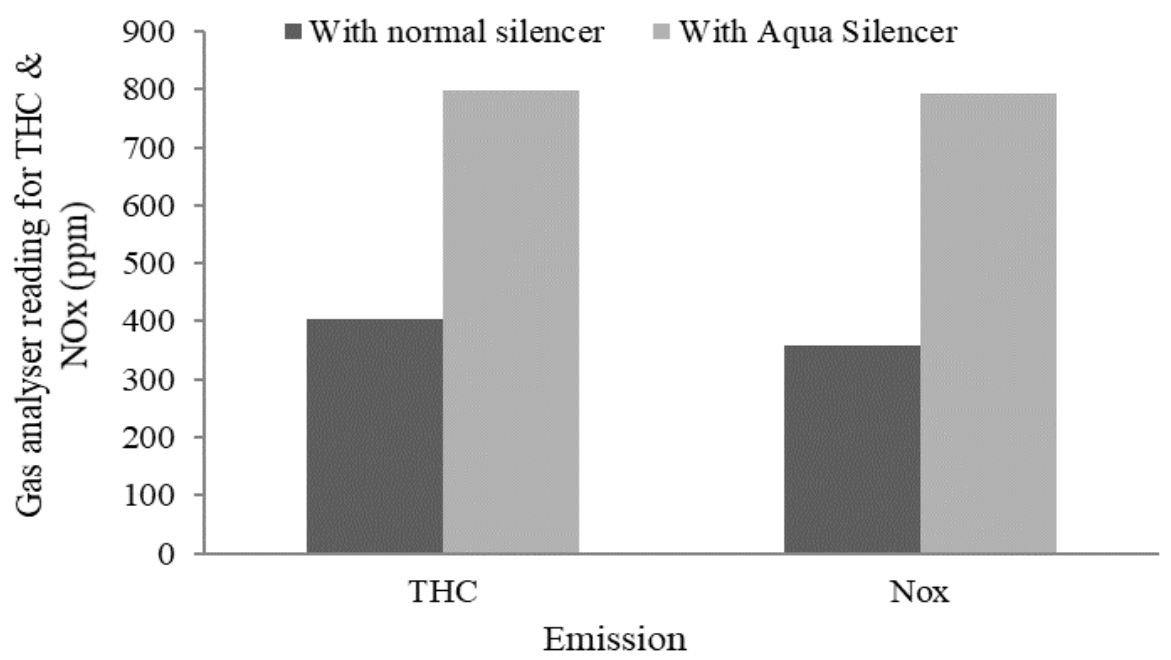

(a)

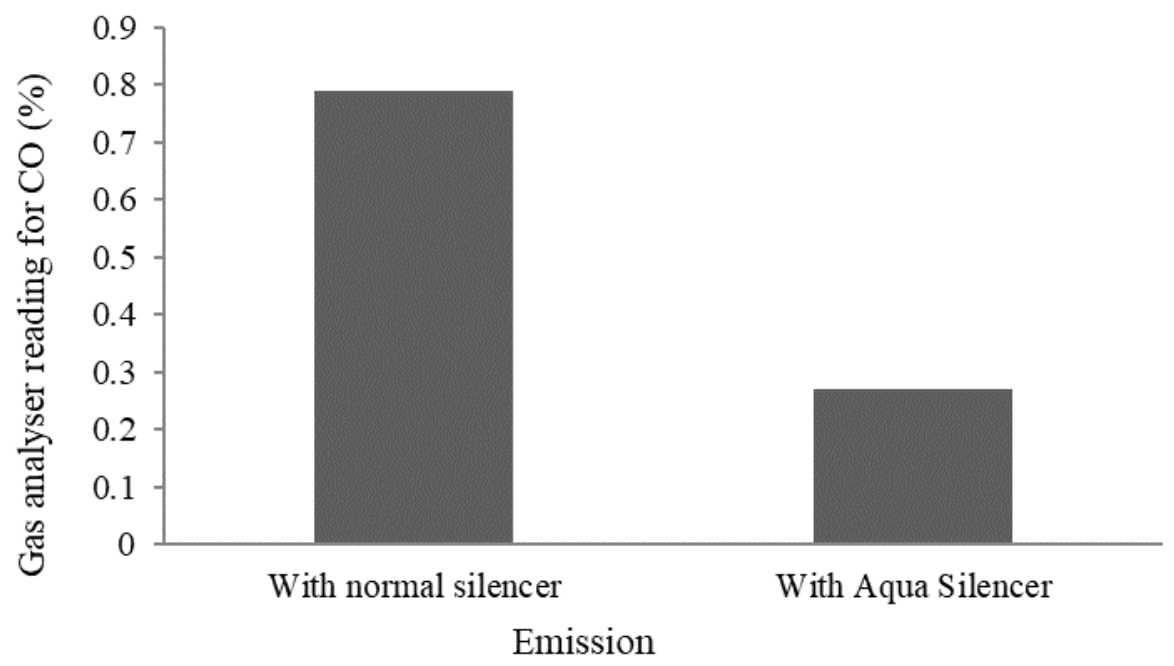

(b)

Figure 6. Regulated emissions at full load condition for (a) $\mathrm{THC}, \mathrm{NO}_{\mathrm{x}}$ and; (b) $\mathrm{CO}$.

A significant decrease in $\mathrm{CO}$ and THC (total hydrocarbon) emissions were recorded $\mathrm{CO}$ reduced from 0.79 to $0.27 \%$ while THC reduced from 405 to $359 \mathrm{ppm}$ in Figure 6. But a negligible reduction in $\mathrm{NO}_{\mathrm{x}}$ emission was recorded. The activated carbon 
was supposed to trap and react with the $\mathrm{CO}$ and $\mathrm{THC}$ but not with $\mathrm{NO}_{\mathrm{x}}$. There was not much chemical interaction among water, activated charcoal and $\mathrm{NO}_{\mathrm{x}}$.

\section{Particulate Matter Test}

At above-discussed engine load, the exhaust tailpipe was covered with pristine paper partially to obtain the result. Two sets of result have been recorded; one with aqua silencer and the other with a normal silencer. Data were collected at the starting of acceleration. Next, it was compared with the grey scale to identify the level of pollutant emission and the presence of engine oil expelling out with the exhaust gasses into the atmosphere. Adsorption Process increased the coagulation power of the process. The excessive dose of activated carbon is not harmful. The treatment process of used activated charcoal was very simple and it required nearly no skill. The efficiency of removing colour, odour and taste was quite high. It had excellent properties of attracting gases.

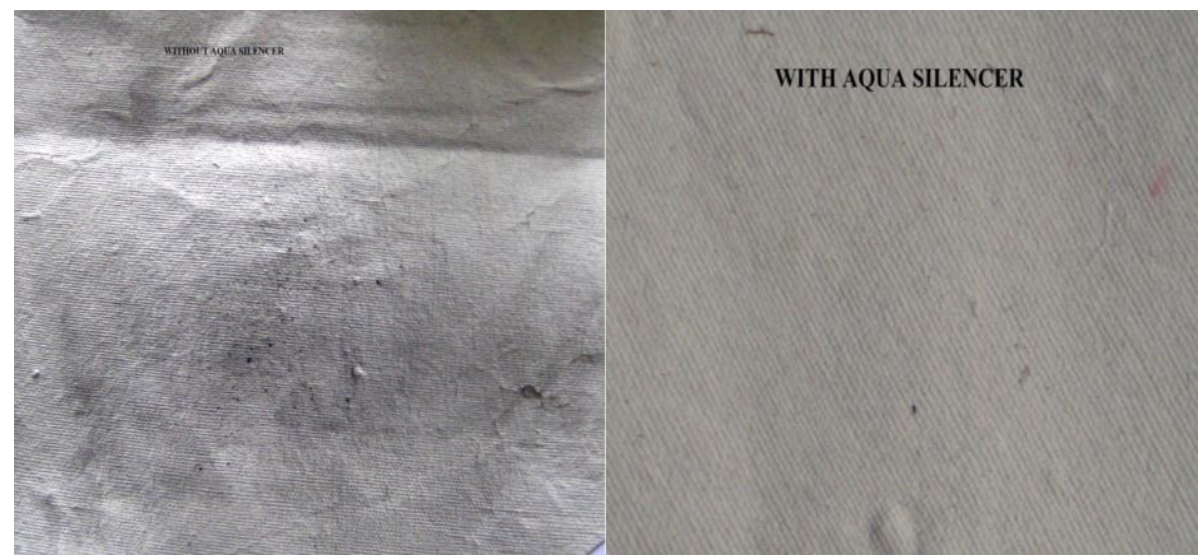

(a)

(b)

Figure 7. Particulate matter results with (a) normal silencer and; (b) aqua silencer.

Particulate matter results were also very significant and shown in Figure8(a). When the conventional silencer was attached to the tailpipe of the engine, the particles were quite visible which shown the presence of high level of particulate matter, shoot particle and engine oil release into the atmosphere. But, in Figure 8(b), when aqua silencer was attached to the tailpipe of the engine, the particles were found negligible. Hence, the addition of the charcoal layer in aqua silencer adsorbed most of the VOC's (volatile organic compounds), and environmental pollutions were decreased. Further, the VOC's (volatile organic compounds) were removed from the aqua silencer by opening drain plug. The contaminated water was sent to the brick factory where water is used to mix clay and soil to make bricks at large scale.

A holder with glass paper was used to measure the particulate matter emission. Three glass papers were taken for collecting the particulate matter reading. The holder was fixed in the tailpipe and reading particulate matter was collected. With the help of micro weighing machine, pre and post weight of the glass paper were measured. The particulate matter readings were collected at $1500 \mathrm{rpm}$ and full load condition. There was a remarkable reduction in the post-measurement of particulate matter of aqua silencer readings. 
Table 4. Result of particulate emission test.

\begin{tabular}{lccc}
\hline Sample & Pre-measurement & $\begin{array}{c}\text { Weight of paper (mg) } \\
\text { Post-measurement with } \\
\text { a normal silencer }\end{array}$ & $\begin{array}{c}\text { Post-measurement with } \\
\text { an aqua silencer }\end{array}$ \\
\hline Paper 1 & 204.79 & 205.81 & 204.84 \\
Paper 2 & 200.76 & 201.29 & 200.88 \\
Paper 3 & 202.98 & 203.31 & 203.01 \\
\hline
\end{tabular}

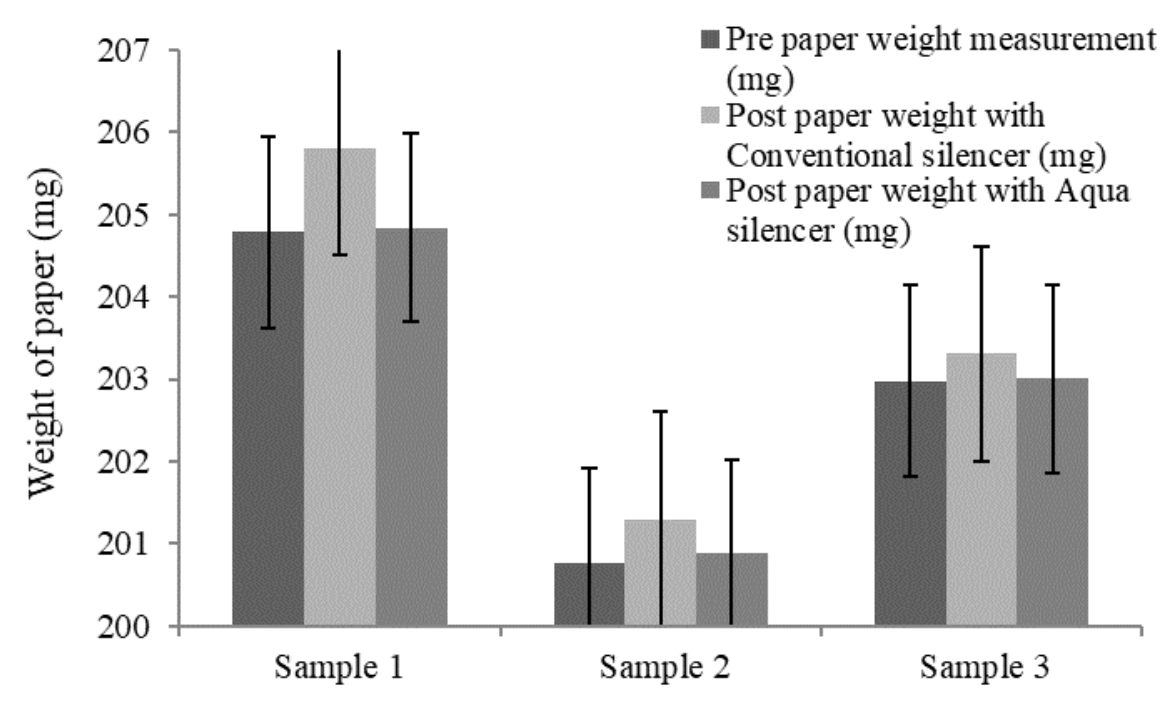

(a)

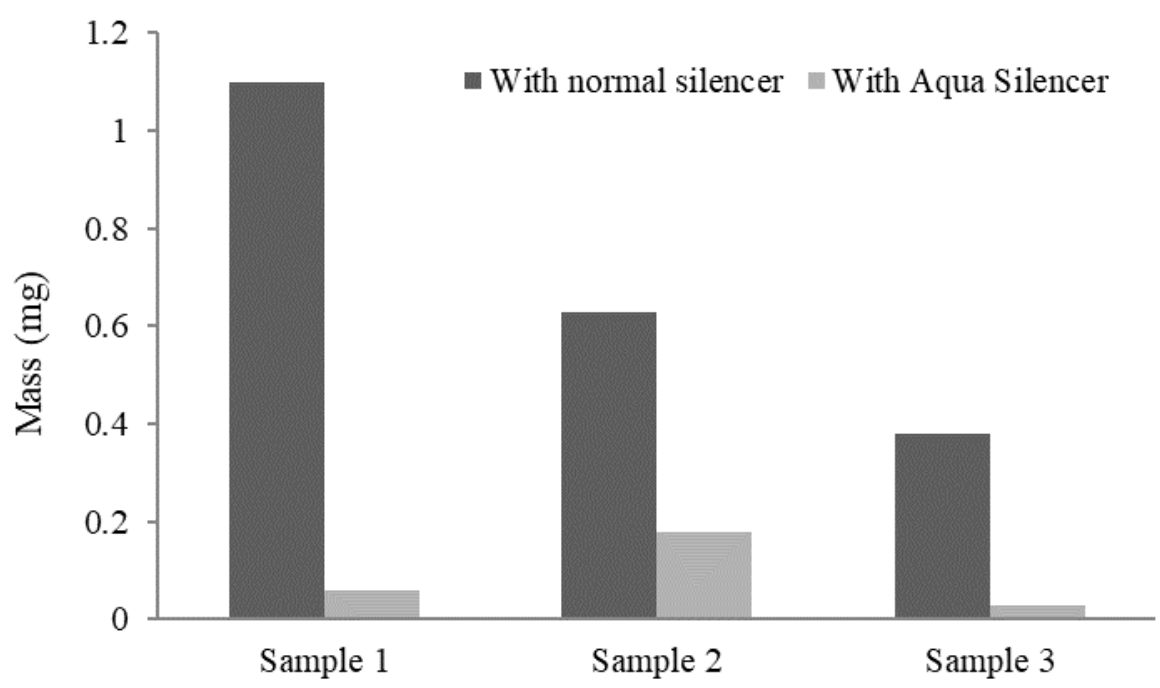

(b)

Figure 8. (a) Differences in weight and; (b) mass emissions of particulate matter with and without an aqua silencer.

\section{Weight Test}

A comparative weight analysis was performed during which the weight of conventional silencer (Philips and Thermo Industries Ltd), conventional aqua silencer with an outer 
shell composed of cast iron and innovative aqua silencer with an outer shell composed of GFR composite were analysed. The results of the analysis are given in Figure 9. It can be observed that by the utilisation of GFR composite for the outer shell of the conventional aqua silencer the weight of the whole unit decreases by $38 \%$ of the conventionally used aqua silencer and is about $24.73 \%$ higher than the conventional silencer. It can also be observed that the weight of conventional aqua silencer is about $53.33 \%$ more than the conventional silencer unit. Therefore, by the utilisation of the GFR aqua silencer unit, a weight saving of about $15.33 \%$ can be achieved in comparison to the conventional aqua silencer unit.

\section{Corrosion}

It can be observed by various studies that the conventional cast iron is not capable of corrosion resistance. Water consists of several salts such as carbonates, sulphides, chlorides, mercuric salts etc. These salts can severely affect cast iron. The salts such as carbonates and sulphides chemical reaction to form alkaline solutions, and thus the rate of corrosion is less in cast iron with the presence of such salts in comparison to chlorides and mercuric salts which chemically react to form acidic solution [11]. However, the fibre composites are corrosion and chemical resistant and therefore have almost negligible corrosion over time if used as an alternate material for cast iron increase the life of the aqua silencer [12].

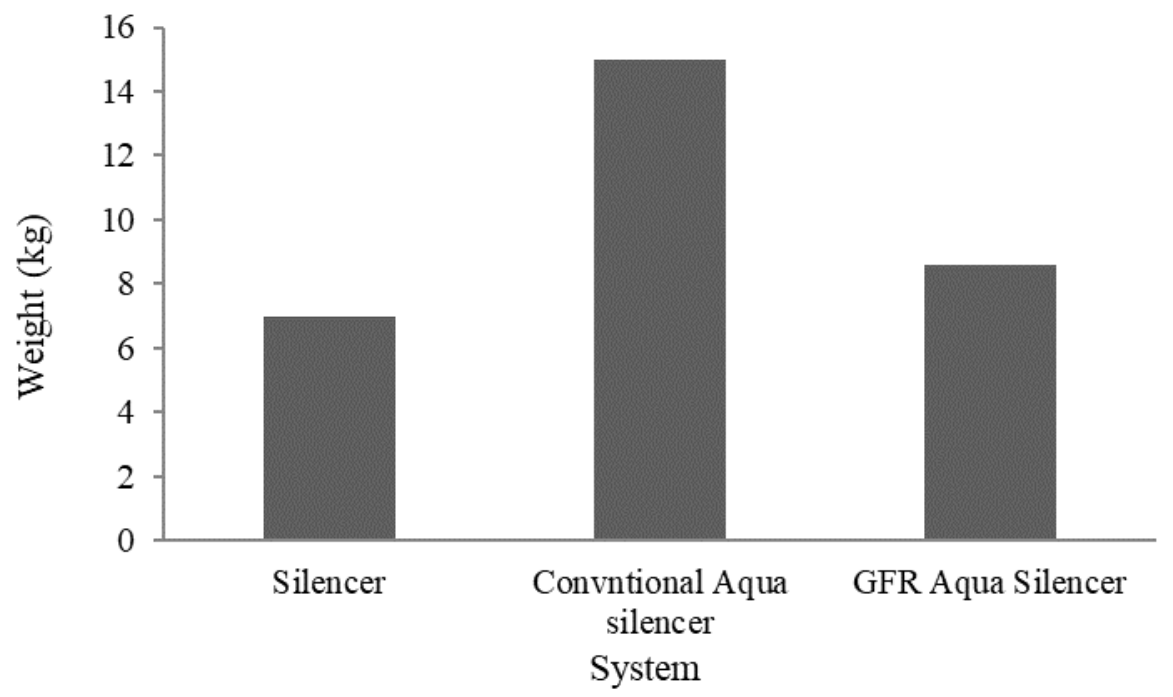

Figure 9. Weight comparison of silencer, conventional aqua silencer and GFR aqua silencer.

\section{CONCLUSION}

The prime focus of this testing was to develop and investigate an innovative GFR aqua silencer performance based on noise, weight and particulate matter filter. The utilisation of the GFR aqua silencer thus developed results in an efficient reduction of the harmful emissions from the engine exhaust system. The installation of perforated tube assists in maintaining the back-pressure constant and reducing the fuel consumption to 226.54 $\mathrm{g} / \mathrm{kw}-\mathrm{hr}$. The sound level decrease by the order of $54 \mathrm{~dB}$ to $38 \mathrm{~dB}, 72 \mathrm{~dB}$ to $49 \mathrm{~dB}, 87 \mathrm{~dB}$ to 
$58 \mathrm{~dB}$ and $105 \mathrm{~dB}$ to $75 \mathrm{~dB}$ at $25 \%, 50 \%, 75 \%$ and full load conditions respectively by the utilization of water as the medium. By using activated charcoal in water, the oil, soot and particulate matter were reduced to a greater extent. The reduction in regulated emissions was also observed. The reduction in particulate matter was also tested through glass paper.

The withdrawal water from the aqua silencer was sent to the brick factory for brick production to replace the use of drinking water in brick production as it is negligibly contaminated. It was without particulate matter and pollution free emission (CO reduced from 0.79 to $0.27 \%$ ) and very economical. It could also be used both for two wheelers and four wheelers but best suited for industry, where there used to have availability of water treatment facility.

The drawbacks associated with the conventional aqua silencer unit were also removed with the utilisation of GFR composite in the innovative aqua silencer unit. When the outer shell of the innovative Aqua silencer was composed of GFR composites, it was observed that by the utilisation of the GFR aqua silencer unit weight saving of about $15.33 \%$ was achieved in comparison to the conventional aqua silencer unit. Also, the problem of corrosion was reduced to almost zero with the utilisation of GFR composite as it is corrosion resistant.

The hazardous emission from the automotive sector has been directly discharged to the environment for decades. The aqua silencer is the perfect solution to the problems arising from the direct perilous exhaust. The conventional aqua silencer can only be installed in heavy and bulky vehicles due to its large weight. But the innovative the technique utilised in the current paper substitutes the metallic outer shell of the aqua silencer by the GFR outer shell, which one of the largest weighing elements in the aqua silencer. This innovative technique has great potential for its implementation in lightweight automotive sector. The current aqua silencer can be installed in lightweighting vehicles without compromising on several factors such as efficiency and power, while at the same time reducing the hazardous emissions and maintaining the aerodynamic stability of the vehicles.

\section{REFERENCES}

[1] Bond SW, Alvarez R, Vollmer MK, Steinbacher M, Weilenmann M, Reimann S. Molecular hydrogen (H2) emissions from gasoline and diesel vehicles. Science of the Total Environment. 2010; 408(17): 3596-606.

[2] Dallmann TR, DeMartini SJ, Kirchstetter TW, Herndon SC, Onasch TB, Wood EC, Harley RA. On-road measurement of gas and particle phase pollutant emission factors for individual heavy-duty diesel trucks. Environmental Science and Technology. 2012; 46(15): 8511-8.

[3] Rai PK. Impacts of particulate matter pollution on plants: Implications for environmental biomonitoring. Ecotoxicology and Environmental Saftey. 2016; 129: 120-36.

[4] Bozlaker A, Spada NJ, Fraser MP, Chellam S. Elemental characterization of PM2.5 and PM10 emitted from light duty vehicles in the Washburn Tunnel of Houston, Texas: release of rhodium, palladium, and platinum. Environmental Science and Technology. 2014; 48(1): 54-62.

[5] Goines L, Hagler L. Noise pollution: a modem plague. Southern Medical Journal. 2007; 100(3): 287-94. 
[6] Warnaka GE, Miller HT, Zalas JM. Structural damping as a technique for industrial noise control. American Industrial Hygiene Association Journal. 1972; 33(1): 1-11.

[7] Tyagi RK, Ranjan R. Effect of heating the catalytic converter on emission characteristic of gasoline automotive vehicles. International Journal of Ambient Energy. 2015; 36(5): 235-241.

[8] Bhandwal M, Kumar M, Sharma M., Srivastava U, Verma A, Tyagi RK. The effect of using the turbulence enhancement unit before the catalytic converter in diesel engine emissions. International Journal of Ambient Energy. 2018; 39(1): 73-77.

[9] Ranjan R, Tyagi RK. Emission characteristic of hydrogen and gasoline blend in spark-ignited engine. International Journal of Ambient Energy. 2017; 38(1): 1418.

[10] Demir B, Henderson LC, Walsh TR. Design Rules for Enhanced Interfacial Shear Response in Functionalized Carbon Fiber Epoxy Composites. ACS Applied Materials and Interfaces. 2017; 9(13): 11846-11857.

[11] Mukesh K, Panday YD. Chemical corrosion in cast iron in soil-water medium. Environmental Technology. 2001; 22(2): 137-50.

[12] McKenna G, Bradley GW, Dunn HK, Statton WO. Degradation resistance of some candidate composite biomaterials. Journal of Biomedical Materials Research. 1979; 13(5): 783-98. 